\title{
What Ecology?
}

TATIANA CARBONELL

Profesora Instructora, Escuela de Arquitectura

Pontificia Universidad Católica de Chile
The plain between two meeting slopes is the topographic condition that Cerros de Chena Park project has recognized in order to create a large irrigated ravine. This operation of water distribution and accumulation is at the service of the introduction of a green mantle. In this manner, the proposal of this project is to generate a condition that did not exist before, that is, a new landscape.

Behind this strategy is a particular vision of ecology at stake: that of man as a creative entity capable of modeling nature, man as a catalytic force of continuous transformations and invention of new forms and programs, doubting nature's role as a carrier of an intrinsic knowledge that should be apprehended and enhanced through restoration measures. In this movement, which questions the relationship between humankind and nature, there is a crisis in the notion of 'natural balance' that breaks the worldview of an ecology that can repair itself. Nature, then, is in itself disturbed, which raises a suspicion about the normative power that is inscribed in it when it is affirmed on a universal principle. In this way, the natural is rejected as something granted and as a solid and functional basis that would support the ethical judgments of social and territorial practices. From this perspective, the sustainable planning activities that are legitimized are called into question, referring to the fact that ecology must return to its 'natural balance'.

Faced with this notion, the commitment of the Cerros de Chena park projects produces a new landscape that triggers an entirely artificial ecology. This grand ravine is sustained by making claeat that ecology is not objective, but responds to an ideological issue. Well, if the implementation of parks would always be something intrinsically positive and in support of city balance, then we would be witnessing a depoliticization of ecology. ARQ 